\title{
Validation of a self-administered web-based 24-hour dietary recall among pregnant women
}

\author{
Claudia Savard ${ }^{1,2,3}$, Simone Lemieux ${ }^{1,3}$, Jacynthe Lafrenière ${ }^{1,3}$, Catherine Laramée ${ }^{3}$, Julie Robitaille ${ }^{1,2,3}$ \\ and Anne-Sophie Morisset ${ }^{1,2,3^{*}}$ (D)
}

\begin{abstract}
Background: The use of valid dietary assessment methods is crucial to analyse adherence to dietary recommendations among pregnant women. This study aims to assess the relative validity of a self-administered Web-based 24-h dietary recall, the R24W, against a pen-paper 3-day food record (FR) among pregnant women.

Methods: Sixty (60) pregnant women recruited at $9.3 \pm 0.7$ weeks of pregnancy in Quebec City completed, at each trimester, 3 R24W and a 3-day FR. Mean energy and nutrient intakes reported by both tools were compared using paired Student T-Tests. Pearson correlations were used to analyze the association between both methods. Agreement between the two methods was evaluated using cross-classification analyses, weighted kappa coefficients and Bland-Altman analyses.

Results: Pearson correlation coefficients were all significant, except for vitamin $\mathrm{B}_{12}(r=0.03 ; p=0.83)$ and ranged from 0.27 to $0.76(p<0.05)$. Differences between mean intakes assessed by the R24W and the FR did not exceed $10 \%$ in 19 variables and were not significant for 16 out of 26 variables. In cross-classification analyses, the R24W ranked, on average, $79.1 \%$ of participants in the same or adjacent quartiles as the FR.

Conclusions: Compared to a 3-day FR, the R24W is a valid method to assess intakes of energy and most nutrients but may be less accurate in the evaluation of intakes of fat (as a proportion of energy intake), vitamin D, zinc and folic acid. During pregnancy, the R24W was a more accurate tool at a group-level than at an individual-level and should, therefore, be used in an epidemiological rather than a clinical setting. The R24W may be particularly valuable as a tool used in cohort studies to provide valid information on pregnant women's dietary intakes and facilitate evaluation of associations between diet and adverse pregnancy outcomes.
\end{abstract}

Keywords: Validation, Dietary assessment, 24-h dietary recall, Dietary intakes, Pregnancy, Pregnant women

\section{Background}

Accurate assessment of dietary intakes is a major pillar of nutrition research, counseling and intervention [1]. The use of valid dietary assessment tools is essential to compare dietary intakes to current nutritional recommendations and to measure associations between diet and health outcomes [2,3]. Dietary assessment is especially important during pregnancy, as inadequate or

\footnotetext{
* Correspondence: anne-sophie.morisset@fsaa.ulaval.ca

'École de nutrition de I'Université Laval, Pavillon Paul-Comtois, Université Laval, 2425, rue de l'Agriculture, local 2412, Québec G1V 0A6, Canada

${ }^{2} A x e$ d'endocrinologie et de néphrologie du Centre de Recherche du CHU de Québec-Université Laval, Québec, QC, Canada

Full list of author information is available at the end of the article
}

excess nutrition during this period can adversely affect both the mother and the fetus [4-6]. Considering that pregnant women's dietary needs and intakes are influenced by numerous endo- and exogenous factors, evaluating the adequacy of diet throughout pregnancy can be complex. Physiological changes occurring in pregnancy, such as rises in blood volume, extracellular liquids, adipose tissue and placental weight, lead to an increase in dietary requirements and can heighten or suppress appetite [7, 8]. Moreover, nausea, attitudes and behaviors towards food, body image perception as well as socioeconomic status have all been known to impact pregnant women's food intakes [9-11].

(c) The Author(s). 2018 Open Access This article is distributed under the terms of the Creative Commons Attribution 4.0 International License (http://creativecommons.org/licenses/by/4.0/), which permits unrestricted use, distribution, and reproduction in any medium, provided you give appropriate credit to the original author(s) and the source, provide a link to the Creative Commons license, and indicate if changes were made. The Creative Commons Public Domain Dedication waiver (http://creativecommons.org/publicdomain/zero/1.0/) applies to the data made available in this article, unless otherwise stated. 
In pregnant women, as in the general population, food records (FR) are known as the gold standard for dietary assessment $[12,13]$. Despite their validity, FR and other pen-paper dietary assessment methods are time consuming, both for participants and research personnel. FR are also prone to a high social desirability bias [2, 14]. For these reasons, web-based FR and web-based recall methods, such as food frequency questionnaires (FFQ) and 24-h dietary recalls, are gaining popularity. Compared to traditional/pen-paper methods, web-based methods are more cost and time effective as they can generate nutritional data automatically and are less prone to data entry errors [15-17]. It has also been reported that web-based tools tend to enhance completion rates by reducing the burden associated with pen-paper dietary assessment methods [18]. For example, contrary to FR, FFQ and dietary recalls are less time consuming because they do not require the participant to weigh or measure every food item consumed. [19]. On the other hand, both FFQ and dietary recalls are subject to memory bias, as participants are asked to report their dietary intakes retrospectively [20]. Moreover, FFQ are more often used to evaluate diets over longer periods of time (e.g. 1 to 12 months), as opposed to dietary recalls, which generally assess short-term dietary intakes [2, 19]. Therefore, in a context like pregnancy, where various factors can impact appetite on a daily basis, using multiple 24-h dietary recalls might provide the most accurate estimate of pregnant women's dietary intakes [4, 21].

Although web-based 24-h dietary recalls are now more frequent in epidemiological studies, very few have been validated in a pregnant population [22]. Since the validation of a dietary assessment tool in the target population is a necessary first step prior to interpreting and generalizing data $[23,24]$, this study aims to assess the relative validity of a self-administered web-based $24-\mathrm{h}$ dietary recall (R24W) against a 3-day FR among a population of French Canadian pregnant women. We hypothesize that the R24W is a valid tool to assess dietary intakes in pregnant women.

\section{Methods}

\section{Participants}

Eighty-six (86) pregnant women recruited from April 2016 to May 2017 at the CHU de Québec - Université Laval (Québec, Canada) were included in the ANGE project (Apports Nutritionnels Durant la Grossesse). The general aim of the ANGE study was to evaluate dietary intakes throughout pregnancy in association with nutritional recommendations, gestational weight gain, glucose tolerance and metabolic profile. Women younger than 18 years old and with a gestational age greater than 12 weeks of pregnancy at the time of recruitment were excluded. Women with a previously diagnosed disease affecting their metabolic profile and/or their dietary intakes (i.e. Type 1 and type 2 diabetes, renal disease, inflammatory and immunity disorders) were also excluded. For the validation analyses, our final sample was restricted to women who completed both the 3FR and the R24W on three occasions within each trimester $(n=60)$. The ANGE project was approved by the $\mathrm{CHU}$ de Québec - Université Laval Research Center's Ethical Committee and participants gave their informed written consent at their first visit to the research center.

\section{The automated web-based 24-h recall (R24W)}

In the $1^{\text {st }}$ (range: $7-14$ weeks), $2^{\text {nd }}$ (range: $20-27$ weeks) and $3^{\text {rd }}$ (range: $31-38$ weeks) trimesters of pregnancy, each participant was asked to complete a total of 3 R24W on 2-week days and 1-weekend day (total of 9 R24W throughout pregnancy). The development of the R24W has been previously described [25]. Briefly, the R24W uses a sequence of questions inspired by the USDA's Automated Multiple Pass Method (AMPM) [26]. In contrast to the AMPM, the R24W uses a mealbased approach in its 1st step. The application also sends automatic e-mails on randomly chosen dates to remind the participants to complete the R24W. Participants are required to watch a mandatory tutorial video prior to their first R24W. The database includes 2865 food items that are linked to the Canadian Nutrient File [27] to enable automatic extraction of nutrient values. Participants can report an unlimited number of meals and snacks for a $24-\mathrm{h}$ period. The database also includes a total of 687 recipes created to ease the entry of mixed dishes (e.g. spaghetti with meat sauce, salads, etc.). Pictures depicting multiple portion sizes with corresponding units and/or volume are available for more than $80 \%$ of all food items. After selecting a food item, participants must choose the picture that best represents the amount of food eaten. In addition, systematic questions are asked about frequently forgotten food items including toppings, condiments, fats, snacks and drinks. The R24W performed well in a validation study where the real dietary intakes of 62 non pregnant adults were known [28] and a pre-test revealed that 29 adults found the R24W easy to understand and complete [25].

\section{3-day food record}

At baseline (range: 7-14 weeks), in the $2^{\text {nd }}$ trimester (range: $20-27$ weeks) and in the $3^{\text {rd }}$ trimester (range: $31-$ 38 weeks), participants were given a three 3-day FR to complete on 2-week days and 1-weekend day (total of 3 FR throughout pregnancy). A trained dietician gave, at baseline, detailed explanations to each participant on how to complete their FR. Written instructions, a list of frequently forgotten food items and an example of a correctly completed FR were also provided to the 
participants. Participants were not required to weigh the foods consumed but were asked to measure their food with household measurements (cups, teaspoons) and indicate a commercial product's brand when applicable. Participants were also asked to provide detailed information about mixed dishes consumed, either by writing, printing, or scanning a recipe from a website or a cookbook. Women were highly encouraged to preserve their normal eating habits when completing the FR. When participants gave back their FR, completeness and portion sizes were reviewed by the same or another trained dietician.

\section{Nutritional analyses}

In each trimester, the R24W and FR were completed on different days. This was established because the R24W requires a participant to recall the foods consumed on the previous day and thus, having completed a FR for the same day would help a participant remember each food eaten. All food items were coded using the 2015 version of the Canadian Nutrient File [27], either automatically, for the R24W, or with Nutrific software (Laval University, Quebec) for the FR. Data from FR was analyzed and initially coded by a research assistant. A trained dietician reviewed data entry and coding for mistakes or omissions. Data for energy and 22 nutrients were analyzed for both the FR and the R24W. Dietary supplement intakes were not considered in the analyses.

\section{Other variables}

Pre-pregnancy body weight was self-reported and height was measured at baseline to calculate pre-pregnancy BMI. Web questionnaires regarding pregnancy related variables (i.e. presence of nausea, vomiting, food cravings, etc.) were completed at each trimester and a socio-economic Web questionnaire was completed once during pregnancy.

\section{Statistical analyses}

At each trimester, means and standard deviations for energy, macro- and micronutrient intakes as well as percentage of energy from carbohydrates (\% carbohydrates), fat (\% fat) and proteins (\% proteins) were calculated from the 3-day FR and the 3 R24W. Paired Student ttests were performed to assess the difference between mean intakes reported by the R24W and mean intakes reported by the FR. Percent differences between the 3 R24W and the 3-day FR [(Mean R24W - Mean FR) / Mean FR)] were also calculated. Pearson correlations were used to evaluate the associations between nutrient intakes from the R24W and the FR. Non-normally distributed variables were log or box-cox transformed. Cross-classification analyses were performed to examine the ability of the R24W to classify participants into similar or adjacent quartiles of dietary intakes classified by the FR. Weighted kappa scores were calculated to assess whether or not the results of the cross-classification analyses were attributable to chance only. The BlandAltman analysis, described as the Spearman correlation between the mean of both tools [(Mean R24W + Mean FR) / 2] and the difference between both tools (Mean FR - Mean R24W) for each participant, was used. Differences and correlations were considered statistically significant at $p<0.05$. Finally, all tests (Paired student ttest, percent difference, Pearson correlation, crossclassification and misclassification, weighted kappa score and Bland-Altman analysis) were pooled to obtain a seven-criteria validity analysis, according to the classification suggested by Lombard et al. [29]. A good (G), acceptable (A) or poor (P) score was attributed to each variable for all 7 criteria. Statistical analyses were performed in JMP version 12 (SAS Institute Inc., NC, USA), with the exception of the weighted kappa score, which was calculated with SAS version 9.4 (SAS Institute Inc., NC, USA).

\section{Results}

Characteristics of the participants are presented in Table 1. Our sample included 60 pregnant women with

Table 1 Participants' characteristics $(N=60)$

\begin{tabular}{|c|c|}
\hline Variables & Mean \pm SD or $\mathrm{N}(\%)$ \\
\hline Age (years) & $32.5 \pm 3.5$ \\
\hline BMI $\left(\mathrm{kg} / \mathrm{m}^{2}\right)$ & $25.3 \pm 5.8$ \\
\hline Ethnicity - Caucasian & $59(98.3)$ \\
\hline \multicolumn{2}{|l|}{ Education } \\
\hline High school & $2(3.3)$ \\
\hline College & $9(15.0)$ \\
\hline University & $49(81.7)$ \\
\hline \multicolumn{2}{|l|}{ Household income $^{a}$} \\
\hline$<40,000 \$$ & $3(5.0)$ \\
\hline $40,000-59,999 \$$ & $8(13.3)$ \\
\hline $60,000-79,999 \$$ & $10(16.7)$ \\
\hline $80,000-99,999 \$$ & $13(21.7)$ \\
\hline$>100,000 \$$ & $25(41.7)$ \\
\hline Gestational age at baseline (weeks) & $9.3 \pm 0.7$ \\
\hline \multicolumn{2}{|l|}{ Number of children } \\
\hline None $^{b}$ & $22(36.7)$ \\
\hline 1 & $33(55.0)$ \\
\hline 2 & $4(6.7)$ \\
\hline 3 & $1(1.7)$ \\
\hline \multicolumn{2}{|l|}{ Experienced nausea } \\
\hline $1^{\text {st }}$ trimester & $52(86.7)$ \\
\hline $2^{\text {nd }}$ trimester & $20(33.3)$ \\
\hline $3^{\text {rd }}$ trimester & $14(23.3)$ \\
\hline
\end{tabular}

${ }^{\mathrm{a}}$ For $N=59 ;{ }^{\mathrm{b}}$ Pregnant with their first child 
a mean age of $32.5 \pm 3.5$ years old and an average prepregnancy BMI of $25.3 \pm 5.8 \mathrm{~kg} / \mathrm{m}^{2}$. Ninety-eight percent of our participants were Caucasian and $81.7 \%$ had completed a university degree. In the 1st trimester of pregnancy, almost all participants (86.7\%) reported nauseous symptoms, as opposed to the 2nd and 3rd trimesters, where much smaller proportions of women reported such symptoms.

Five women completed 8 of the 9 required R24W and 2 additional women partially completed one of their 3 FR (2 out of 3 days). We did not exclude these women from our statistical analyses because including them did not affect our results. Completion statistics for the R24W are presented in Table 2. Average R24W completion time significantly decreased at each trimester $(p<0.001)$ and the number of items reported was significantly lower in the 3 rd compared to the 2 nd trimester $(p=0.02)$.

In order to lighten the figures and tables shown in the results section of this article, only 2 nd trimester validity analyses are presented. Results from the 1st and 3rd trimesters are available in the supplementary material, and some of these results are briefly presented throughout the section below. Overall, 2nd trimester results were representative of the association and agreement between the R24W and the FR throughout pregnancy, as they were statistically stronger than the 1st but not the 3rd trimester results.

Table 3 presents differences between the data from R24W and the FR for the 2nd trimester, as well as Pearson correlation coefficients. Mean intakes of energy, fat, \% fat, saturated fatty acids (SFA), cholesterol, vitamin C, vitamin $\mathrm{D}$, magnesium, phosphorus, zinc and calcium were significantly different between both tools (average difference: 12 . $2 \% ; p<0.05)$. Results were similar in other trimesters (Additional file 1: Table S1), as differences between mean R24W and FR intakes were significant for 8 variables in both the 1st (energy, fat, SFA, riboflavin, vitamin D, phosphorus, calcium and sodium; average difference: 13.0\%) and 3rd trimesters (\% fat, SFA, cholesterol, vitamin $\mathrm{B}_{6}$, vitamin $\mathrm{D}$, magnesium, phosphorus and calcium; average difference: $11.4 \%)$. In the 2nd trimester, the highest percent differences were observed for vitamin $\mathrm{D}$ $(20.6 \% ; p=0.02)$ and calcium $(21.6 \% ; p=0.0003)$. Pearson correlation coefficients in the 2nd trimester

Table 2 Completion statistics of the R24W

\begin{tabular}{|c|c|c|c|c|}
\hline & \multicolumn{3}{|l|}{ Mean (SD) } & \multirow[t]{2}{*}{$P$ value } \\
\hline & 1st trimester & 2nd trimester & 3rd trimester & \\
\hline $\begin{array}{l}\text { Completion } \\
\text { time (minutes) }\end{array}$ & $21.8(7.5)$ & $19.2(6.8)$ & $16.3(5.1)$ & $<0.0001$ \\
\hline $\begin{array}{l}\text { Reported } \\
\text { meals (N) }\end{array}$ & $5.1(0.9)$ & $4.8(1.1)$ & $5.0(1.2)$ & 0.13 \\
\hline Reported items (N) & $20.5(4.0)$ & $20.3(4.1)$ & $19.4(4.0)$ & 0.025 \\
\hline
\end{tabular}

ranged from 0.27 to 0.76 and were all significant with the exception of vitamin $\mathrm{B}_{12}(r=0.03 ; p=0.83)$. Similarly, all 3rd trimester correlations were significant, but non-significant correlations were observed for \% fat $(r=0.09 ; p=0.50)$, folic acid $(r=0.20 ; p=0.13)$ and vitamin $\mathrm{B}_{12}(r=0.19 ; p=0.14)$ in the 1st trimester.

The R24W classified 79.1\% (range 68.3-90.0\%) of the participants in the same or adjacent quartile compared with the FR in the $2^{\text {nd }}$ trimester (Table 4). Furthermore, misclassification, i.e. when a participant is classified in the $1^{\text {st }}$ quartile by one tool and in the $4^{\text {th }}$ by the other, occurred in $3.9 \%$ (range $0-10.0 \%$ ) of all cases in the $2^{\text {nd }}$ trimester. Cross-classification analyses revealed similar results in the $1^{\text {st }}$ and $3^{\text {rd }}$ trimesters (Additional file 2: Table S2). Weighted kappa scores ranged from 0.09 to 0 . 49 (average 0.32 ) in the $2^{\text {nd }}$ trimester, with the lowest value being for cholesterol. Significant Spearman correlations between the mean of both tools and the difference between both tools (proportional bias) were observed for cholesterol and niacin in the 2nd trimester (Table 5). A proportional bias was also observed for thiamin and vitamin $\mathrm{C}$ as well as for carbohydrates, \% carbohydrates, \% fat, thiamin, niacin, vitamin B6, folic acid and fibers in the 1st and 3rd trimesters, respectively (Additional file 3: Table S3).

A summary of all agreement and association analyses conducted in the 2nd trimester is presented in Table 5, based on the classification suggested by Lombard et al. [29]. In the 2nd trimester, the number of poor outcomes by variable ranged from 0 (carbohydrates and \% protein) to 4 (vitamin $\mathrm{D}$ and zinc). In the 1 st trimester, \% fat, vitamin $\mathrm{D}$ and folic acid were the variables with the highest number of poor outcomes $(n=4)$, and all 3rd trimester variables accumulated less than 4 poor outcomes each (Additional file 3: Table S3).

\section{Discussion}

This is the first study to assess the relative validity of a web-based 24-h dietary recall in comparison with a 3-day FR among a population of pregnant women in all trimesters. All agreement and association analyses showed that, for most nutrients, the R24W can provide an estimation of pregnant women's dietary intakes that is similar to the one obtained with a 3-day FR. Our results demonstrate that the R24W can be used to evaluate dietary intakes throughout pregnancy. To our knowledge and as mentioned by Vézina-Im et al. (2014) [30], there is a lack of current literature relevant to the use of this type of tool. Therefore, our analyses must be compared with those of studies that validated web-based 24-h dietary recalls against a FR in non-pregnant adult populations.

Overall, Pearson correlations between both tools assessed in the $2^{\text {nd }}$ trimester of pregnancy have shown good associations. Indeed, our results revealed that 14 
Table 3 Differences between mean dietary intakes reported by the R24W and the FR in the 2nd trimester

\begin{tabular}{|c|c|c|c|c|}
\hline & R24W (SD) & FR (SD) & $\%$ difference & Pearson correlation \\
\hline Energy (kcal) & $2357(489)$ & $2239(506)$ & $5.3^{*}$ & $0.68^{*}$ \\
\hline Carbohydrates (g) & $286.7(67.7)$ & $279.1(76.2)$ & 2.7 & $0.76^{*}$ \\
\hline Fat (g) & $94.3(26.1)$ & $84.9(22.6)$ & $11.1^{*}$ & $0.60^{*}$ \\
\hline Proteins (g) & $99.6(20.1)$ & $98.5(22.6)$ & 1.1 & $0.37^{*}$ \\
\hline$\%$ Carbohydrates & $48.7(5.4)$ & $49.7(6.0)$ & -2.0 & $0.53^{*}$ \\
\hline$\%$ Fat & $35.8(4.9)$ & $34.1(4.8)$ & $5.0^{*}$ & $0.48^{*}$ \\
\hline$\%$ Proteins & $17.2(3.0)$ & $17.8(3.1)$ & -3.4 & $0.58^{*}$ \\
\hline SFA (g) & $34.7(11.7)$ & $30.3(10.4)$ & $14.5^{*}$ & $0.48^{*}$ \\
\hline Cholesterol (mg) & $289.4(95.2)$ & $322.6(134.4)$ & -10.3 & $0.29^{*}$ \\
\hline Vitamin A $(\mu \mathrm{g})$ & $943.6(412.4)$ & $932.0(630.3)$ & 1.2 & $0.31^{*}$ \\
\hline Thiamin (mg) & $2.0(0.6)$ & $1.9(0.6)$ & 5.3 & $0.68^{*}$ \\
\hline Riboflavin (mg) & $2.4(0.6)$ & $2.3(0.7)$ & 4.3 & $0.46^{*}$ \\
\hline Niacin (mg) & $26.7(5.7)$ & $27.2(9.3)$ & -1.8 & $0.48^{*}$ \\
\hline Vitamin B6 (mg) & $1.9(0.5)$ & $1.9(0.6)$ & 0 & $0.44^{*}$ \\
\hline Folic Acid $(\mu \mathrm{g})$ & $400.5(100.8)$ & $405.9(144.1)$ & -1.3 & $0.54^{*}$ \\
\hline Vitamin B12 $(\mu \mathrm{g})$ & $5.5(2.6)$ & $5.1(2.6)$ & 7.8 & 0.03 \\
\hline Vitamin C (mg) & $139.9(85.6)$ & $162.0(83.9)$ & $-13.6^{*}$ & $0.69^{*}$ \\
\hline Vitamin D (IU) & $272.0(132.6)$ & $225.6(131.4)$ & $20.6^{*}$ & $0.27^{*}$ \\
\hline Magnesium (mg) & $398.9(100.4)$ & $359.3(113.9)$ & $11.0^{*}$ & $0.57^{*}$ \\
\hline Phosphorus (mg) & $1678.1(370.8)$ & 1557.1 (384.4) & $7.8^{*}$ & $0.43^{*}$ \\
\hline Zinc (mg) & $13.3(3.1)$ & $11.9(3.0)$ & $11.8^{*}$ & $0.28^{*}$ \\
\hline Iron (mg) & $15.9(4.7)$ & $15.9(4.9)$ & 0 & $0.58^{*}$ \\
\hline Calcium (mg) & $1372.3(500.0)$ & $1128.3(447.0)$ & $21.6^{*}$ & $0.51^{*}$ \\
\hline Potassium (mg) & $3302.9(826.4)$ & 3326.1 (848.5) & -0.7 & $0.62^{*}$ \\
\hline Sodium (mg) & $3322.0(891.3)$ & $3088.9(1038.3)$ & 7.5 & $0.51^{*}$ \\
\hline Dietary fibers (g) & $24.8(8.2)$ & $24.2(6.8)$ & 2.5 & $0.71^{*}$ \\
\hline Average & & & 6.7 & 0.50 \\
\hline
\end{tabular}

${ }^{*}$ T-test and Pearson correlation coefficients with a $P$ value $<0.05$

nutrients had a correlation coefficient above or equal to 0.50 which Masson et al. (2003) [31] identified as the minimal recommended value to qualify a correlation as good. Correlations of this magnitude are, however, expected when two distinct measurement methods are used to assess the same variables (e.g. vitamin D measured by the R24W vs measured by a 3-day FR) $[23,32,33]$. Our results are similar to those of Frankenfeld et al. (2012) [34], who compared 2 web-based 24-h dietary recalls (ASA24) with a 4-day dietary record in 93 non pregnant Americans and found correlation coefficients that ranged from 0.06 to 0.76 . Similarly, Timon et al. (2017) [35] compared 2 web-based 24-h dietary recalls (Foodbook24) with a 4-day FR among 40 non pregnant adults and observed correlation coefficients ranging from 0.32 to 0.75 , which is also comparable to our results.
In our study, we observed a correlation coefficient of $0.03(p=0.83)$ for vitamin $\mathrm{B}_{12}$ intakes in the $2^{\text {nd }}$ trimester, indicative of a weak association between the FR and the R24W for this nutrient. Nevertheless, this lack of association does not necessarily mean that the R24W cannot assess vitamin $B_{12}$ intakes accurately. In fact, mean intakes of vitamin $B_{12}$ reported by the R24W and the FR did not differ significantly in the $2^{\text {nd }}$ trimester $(5.5 \pm 2.6 \mu \mathrm{g}$ with the R24W vs $5.1 \pm 2.6 \mu \mathrm{g}$ with the FR; $p=0.46$ ), as well as in the $1^{\text {st }}$ and $3^{\text {rd }}$ trimesters. Moreover, in all trimesters, no proportional bias was observed for vitamin $B_{12}$ intakes. Similarly, even though Frankenfeld et al. (2012) [34] observed a lower correlation coefficient $(r=0.06)$ for vitamin $\mathrm{E}$ intakes reported by the ASA24 and the FR, they found no significant difference between vitamin $\mathrm{E}$ intakes reported by both tools. Likewise, Comrie et al. (2009) [36], who 
Table 4 Cross-classification of intakes by quartiles and weighted kappa coefficient in the 2nd trimester

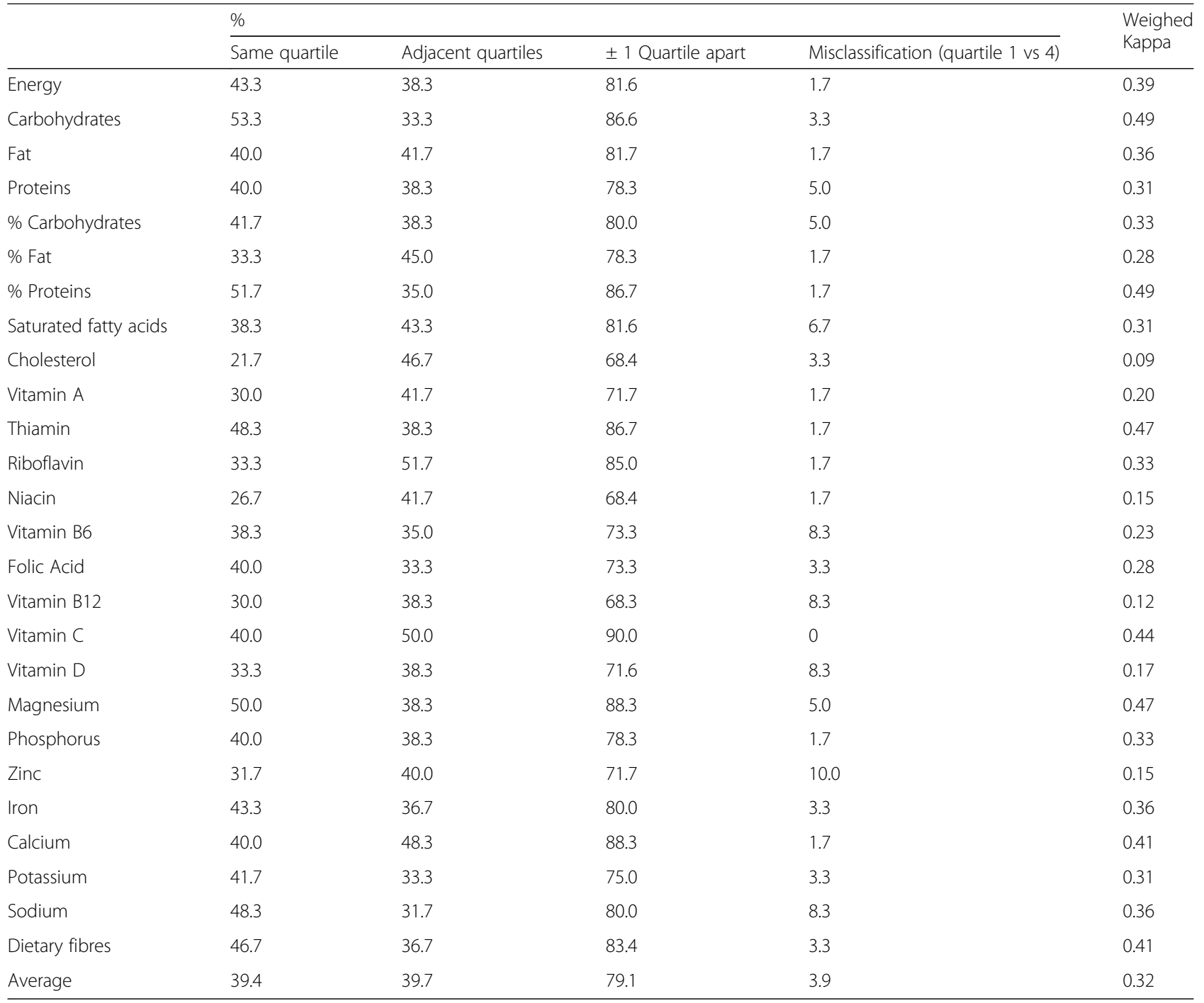

compared a web-based food recall checklist (FoRC) with a 4-day FR among 53 University students, observed a weaker correlation $(r=0.30)$ between intakes of $\%$ fat reported by both tools, but the mean difference between both tools was not significant. Thus, in the present study, we interpret the weak association between both tools for one particular nutrient as a justification to conduct additional tests, such as paired student-t test, crossclassification and Bland-Altman analysis, but not as a justification to invalidate the data [29].

For the majority of nutrients, no significant differences were detected between mean intakes reported by the R24W and the FR, in the 2nd trimester. However, some significant differences were observed for total energy, fat, $\%$ fat, SFA, vitamin C, vitamin D, magnesium, phosphorus, zinc and calcium. For these nutrients, average difference between intakes reported by the FR and the R24W was 12 .
$2 \%$, which is considered as an acceptable gap according to Lombard et al. (2015) [29]. Overall, intakes reported by the R24W were higher than those reported by the FR for 17 out of 26 variables. Similar results were obtained by Timon et al. (2017) [35], where significant differences between the Web-based 24HR and the FR were observed in intakes of $\%$ fat, protein, dietary fibers, riboflavin, iron, potassium and sodium. In comparison, De Keyzer et al. (2011) [37] compared two computer assisted 24-h recalls (24HR) with a 5-day FR and found significant differences between intakes of energy and 8 nutrients (fat, fatty acids, cholesterol, alcohol, vitamin $\mathrm{C}$, thiamine, riboflavin and iron) reported by both tools. Furthermore, De Keyzer et al. (2011) [37] also observed higher intakes with the 24HR than with the FR and suggested it might be due to portion size estimation by food photographs. In fact, although photographs are generally useful to accurately recall 
Table 5 Seven criteria validity analysis of the R24W in the $2^{\text {nd }}$ trimester

\begin{tabular}{|c|c|c|c|c|c|c|c|}
\hline & \multicolumn{3}{|l|}{ Individual level } & \multicolumn{3}{|l|}{ Group level } & \multirow[t]{3}{*}{ Total of poor outcome } \\
\hline & \multirow{2}{*}{$\begin{array}{l}\text { Association } \\
\text { Pearson coefficient }\end{array}$} & \multicolumn{2}{|l|}{ Agreement } & \multicolumn{2}{|l|}{ Agreement } & \multirow{2}{*}{$\begin{array}{l}\text { Presence of bias } \\
\text { Bland- Altman }\end{array}$} & \\
\hline & & Cross-classification & Kappa score & $\%$ difference & T-test & & \\
\hline $\begin{array}{l}\text { Criteria for good } \\
\text { (G) outcome }\end{array}$ & $\geq 0.50$ & $\begin{array}{l}\geq 50 \% \text { in same quartile; } \\
<10 \% \text { in opposite } \\
\text { quartile }\end{array}$ & $\geq 0.61$ & $0-10.9 \%$ & $P>0.05$ & $P>0.05$ & \\
\hline $\begin{array}{l}\text { Criteria for } \\
\text { acceptable } \\
\text { (A) outcome }\end{array}$ & $0.20-0.49$ & & $0.20-0.60$ & $11.0-20 \%$ & & & \\
\hline $\begin{array}{l}\text { Criteria for } \\
\text { poor }(P) \\
\text { outcome }\end{array}$ & $<0.20$ & $\begin{array}{l}<50 \% \text { in same } \\
\text { quartile; } \geq 10 \% \\
\text { in opposite quartile }\end{array}$ & $<0.20$ & $>20 \%$ & $P \leq 0.05$ & $P \leq 0.05$ & \\
\hline Energy & G & $P-G$ & A & G & $P$ & G & 2 \\
\hline Carbohydrates & G & G-G & A & G & G & G & 0 \\
\hline Fat & G & $P-G$ & A & A & $P$ & G & 2 \\
\hline Proteins & A & $P-G$ & A & G & G & G & 1 \\
\hline \% Carbohydrates & G & $P-G$ & A & G & G & G & 1 \\
\hline$\%$ Fat & A & $P-G$ & A & G & $P$ & G & 2 \\
\hline$\%$ Proteins & G & G-G & A & G & G & G & 0 \\
\hline SFA & A & $P-G$ & A & A & $P$ & G & 2 \\
\hline Cholesterol & A & $P-G$ & $P$ & G & G & $P$ & 3 \\
\hline Vitamin A & A & $P-G$ & A & G & G & G & 1 \\
\hline Thiamin & G & $P-G$ & A & G & G & G & 1 \\
\hline Riboflavin & A & $P-G$ & A & G & G & G & 1 \\
\hline Niacin & A & $P-G$ & $P$ & G & G & $P$ & 3 \\
\hline Vitamin B6 & A & $P-G$ & A & G & G & G & 1 \\
\hline Folic Acid & G & $P-G$ & A & G & G & G & 1 \\
\hline Vitamin B12 & $P$ & $P-G$ & $P$ & G & G & G & 3 \\
\hline Vitamin C & G & $P-G$ & A & A & $P$ & G & 2 \\
\hline Vitamin D & A & $P-G$ & $P$ & P & $P$ & G & 4 \\
\hline Magnesium & G & G-G & A & A & $P$ & G & 1 \\
\hline Phosphorus & A & $P-G$ & A & G & $P$ & G & 2 \\
\hline Zinc & A & P-P & $P$ & A & $P$ & G & 4 \\
\hline Iron & G & $P-G$ & A & G & G & G & 1 \\
\hline Calcium & G & $P-G$ & A & $P$ & $P$ & G & 3 \\
\hline Potassium & G & $P-G$ & A & G & G & G & 1 \\
\hline Sodium & G & $P-G$ & A & G & G & G & 1 \\
\hline Dietary fibres & G & $P-G$ & A & G & G & G & 1 \\
\hline $\begin{array}{l}\text { Total of poor } \\
\text { outcomes }\end{array}$ & 1 & $23-1$ & 5 & 2 & 10 & 2 & 44 \\
\hline Average & & & & & & & 1.7 \\
\hline
\end{tabular}

portion size, some studies have mentioned considerable over and/or underestimations of the real amount of food eaten when participants were asked to use photographs to recall their food intakes [38-40]. On the other hand, a previous validation study comparing the R24W with known dietary intakes found that the self-reported portion sizes were, on average, only $3.2 \mathrm{~g}$ higher than the real portion sizes offered to participants [28]. However, the same study observed that portion sizes smaller than $100 \mathrm{~g}$ were significantly overestimated by $17.1 \%$. This could partially explain why, in our study, energy, fat, $\%$ fat and SFA intakes were higher when reported by the R24W, as smaller 
portioned food items include fats, sauces, toppings and cheese [28]. Significantly higher intakes observed with the R24W could also be explained by the presence of social desirability and reactivity bias, both frequently observed with the FR $[2,14]$. Therefore, it is possible that our participants had an increased tendency to underestimate and/ or underreport portion sizes when completing the FR in comparison to when they completed the R24W.

Cross-classification analyses in the 2nd trimester revealed an acceptable agreement on an individual-level between the R24W and the FR. Classification of participants in the same and in the same or adjacent quartiles averaged 39.4\% (range: 21.7-53.3\%) and 79.1\% (range: 68 . $3-90.0 \%)$, respectively. These results are similar to those observed by Frankelfeld et al. (2012) [34] and Timon et al. (2017) [35] in which ranking of participants in the same or adjacent quartiles ranged from $62.6 \%$ to $79.8 \%$ and from $69.2 \%$ to $92.3 \%$, respectively. Moreover, in our study, only zinc was characterized by a gross misclassification (opposing quartiles) of more than $10 \%$ of participants. This is especially important since the ability of a method to accurately rank participants according to their dietary intakes is essential in the evaluation of dietdisease associations [23]. Furthermore, weighted kappa scores averaged 0.32, thus representing an acceptable agreement according to the terminology of Lombard et al. [29] and indicating that the ranking of participants in the same or adjacent quartiles was not attributable to chance [29]. It is important to mention that a perfect agreement between the R24W and the FR was very unlikely to be observed, considering that both tools did not evaluate dietary intakes on the same 3 days. Moreover, since within-person day-to-day variability is high for both 24-h dietary recalls and FR and since both tools were completed on 3 different days, the ranking of participants is complex [41]. Day-to-day variability may be further enhanced during pregnancy, as pregnant women's dietary intakes may be influenced by nausea and vomiting. [42]. It is possible that some women experienced more nausea and vomiting during the 3 days they completed the FR compared to the 3 R24W days, or vice-versa. Thus, a woman could have been ranked in the 1st quartile according to her intakes reported by one tool and in the 3rd or 4th quartile according to her intakes reported by the other tool. For these reasons, weighted kappa coefficients and the results of crossclassification analyses should be interpreted with caution and in combination with the other validity analyses conducted in this study.

As previously mentioned, analyses conducted in the 3rd trimester were statistically stronger when compared to those of the 1st and 2nd trimesters, thus suggesting a greater relative validity in the 3rd trimester. This might be explained, in part, by participant's increased experience and comfort with completing both tools towards the end of their pregnancy. By the third trimester, participants had completed six R24W and two 3-day FR. This could also partially explain the significant decrease in completion time across trimesters of pregnancy. Moreover, fewer participants reported experiencing nausea in the 3rd trimester, which may also explain why there were less variations between dietary intakes recorded by the last R24W and FR, compared with the 1st and 2nd trimesters. Since our study is the first to assess the validity of a web-based $24-\mathrm{h}$ recall in all trimesters of pregnancy, we were not able to compare our results to previous literature and these suppositions should be interpreted with caution.

In the 2nd trimester, only 2 (vitamin D and zinc) out of 26 variables accumulated a total of 4 poor association and agreement outcomes. Similar results were observed in the 1st (\% fat, folic acid and vitamin D) and 3rd trimesters. Lombard et al. (2015) [29] suggested that nutrients with the highest number of poor outcomes, \%fat, folic acid, vitamin D and zinc in our results, might not be consumed on a daily basis by the studied population and would be better assessed by a FFQ rather than a R24W or a FR. This is of particular interest considering that folic acid is essential during pregnancy and plays an important role in fetal growth and development [43, 44]. Moreover, deficiencies in folic acid are associated with higher risk of birth defects, particularly neural tube defects [44]. Thus, an inaccurate intake estimation of this nutrient could be harmful, especially among pregnant women that are less compliant with their prenatal dietary supplements [45]. The combined use of a FFQ with the R24W and even biomarker analyses should, therefore, be considered to accurately assess dietary intakes of folic acid, vitamin D and zinc [29]. Globally, better results were observed with the group-level analyses (paired Student t-test and Bland-Altman analysis) in comparison with individual validity outcomes (Pearson correlation, cross-classification analysis and weighted kappa coefficient). This greater validity on a group-level in comparison to individual-level was also observed by Comrie et al. (2009) [36], although this study did not use all 7 statistical analyses conducted in the present study. However, the accuracy of dietary assessment at an individual level (i.e. when the assessed intakes of an individual accurately reflects real intakes) is not essential to provide valid and useful data on nutrition and health outcomes [41]. Therefore, the results of our group-level analyses suggest that the R24W is a valid tool to assess average dietary intakes of pregnant women but should be used with caution when counselling dietary changes to pregnant women in a clinical setting. 
To our knowledge, this is the first dietary assessment validation study among pregnant women to compare a web-based 24-h recall with a FR by using seven association and agreement analyses for each pregnancy trimester. This summary analysis allowed a more in depth understanding of the accuracy and precision of the R24W, as well as an identification of the R24W's strengths and limitations. It can be argued that, for a better estimate of usual dietary intakes, additional R24W and FR days would have been needed. Yet, asking our participants to recall and report their dietary intakes for more than 6 days per trimester could have worsened compliance, participation rate, and potentially altered our results. Our validation study also has limited generalizability because our study population was highly educated and almost 100\% Caucasian. In addition, our small study sample $(n=60)$ might have attenuated the strength of some of our statistical analyses, e.g. correlation coefficients and crossclassification. Despite our small study sample, our results showed that the R24W was a relatively valid tool.

\section{Conclusions}

In summary, we observed that compared to the FR, the R24W has good relative validity to assess energy and most nutrients in all trimesters. The R24W did not, however, perform as well for the assessment of intakes of $\%$ fat, vitamin D, folic acid and zinc. The use of combined dietary assessment methods, including FFQs and biomarker analyses, is, therefore, recommended to ensure an accurate estimation of dietary intakes for these nutrients. The R24W demonstrated a greater grouplevel validity compared to an individual-level validity and should, therefore, be used in an epidemiological rather than a clinical setting. Nevertheless, in addition to being less expensive and more effective than pen-paper methods, the R24W has the potential to provide accurate and precise information on pregnant women's dietary intakes, and, therefore allows the evaluation of potential associations between dietary intakes and adverse pregnancy outcomes.

\section{Additional files}

Additional file 1: Table S1. Differences between mean dietary intakes reported by the R24W and the FR in the $1^{\text {st }}$ and $3^{\text {rd }}$ trimesters. This additional file presents differences (Percentage differences and results of Student T-test) between mean dietary intakes reported with the R24W and the FR in the 1st and 3rd trimesters as well as Pearson correlation coefficients. (DOCX $22 \mathrm{~kb}$ )

Additional file 2: Table S2. Cross-classification of intakes by quartiles and weighted kappa coefficient in the $1^{\text {st }}$ and $3^{\text {rd }}$ trimesters. This additional file presents the proportion of participants whose dietary intakes reported by both tools in the 1st and 3rd trimesters were ranked in the same, adjacent and opposite quartiles. (DOCX $20 \mathrm{~kb}$ )
Additional file 3: Table S3. Seven criteria validity analysis of the R24W in the $1^{\text {st }}$ and $3^{\text {rd }}$ trimesters. This additional file presents a summary of all agreement and association analyses conducted in the 1st and 3rd trimesters. (DOCX $21 \mathrm{~kb})$

\section{Abbreviations}

$\%$ carbohydrates: Percentage of total energy from carbohydrates; \% fat: Percentage of total energy from fat; $\%$ proteins: Percentage of total energy from proteins; 24HR: 24-h recall; AMPM: Automated Multiple-Pass Method; ANGE: Apports Nutritionnels durant la GrossessE (Nutritional intakes during pregnancy); ASA24: Automated Self-Administered Recall System; BMI: Body mass index; CHU: University-affiliated Hospital Center; FFQ: Food frequency questionnaire; FR: Food record; R24W: The automated selfadministered 24-h dietary recall developed by Laval University;

SFA: Saturated fatty acids; USDA: United States Department of Agriculture

\section{Acknowledgments}

We would like to acknowledge the valuable collaboration of trained dietician and graduate student Anne-Sophie Plante and undergraduate students Marjorie Labrecque and Joséane Gilbert-Moreau in the data collection and coding. We would also like to thank Jillian Ashley-Martin, Ph.D., for her great contribution in the revision of our manuscript.

\section{Funding}

The ANGE project is funded by the Danone Institute of Canada and by startup founds (Fonds de recherche du Québec-Santé et Fondation du CHU de Québec). All funding allowed the collection, analysis, and interpretation of data, but played no role in the writing of this manuscript.

\section{Availability of data and materials}

The datasets used and/or analysed during the current study that are not presented in this article or in the supplementary material are available from the corresponding author on reasonable request.

\section{Authors' contributions}

All authors made substantial contributions to the conception and design of the manuscript, and all critically revised a first draft of the manuscript for important intellectual content. CS collected the data under the supervision of ASM and conducted primary statistical analyses of the data with the help of $J \mathrm{~L}, \mathrm{CL}, \mathrm{SL}$ and ASM. All authors participated in the secondary analyses and interpretation of data. All authors gave their approval of the manuscript's final version to be published and therefore take public responsibility for the content of the manuscript. Finally, all authors agreed to be accountable for all aspects of the work.

\section{Ethics approval and consent to participate}

The ANGE project was approved by the CHU de Québec - Université Laval Research Center's Ethical Committee and participants gave their written informed consent at their first visit to the research center.

\section{Competing interests}

The authors declare that they have no competing interests.

\section{Publisher's Note}

Springer Nature remains neutral with regard to jurisdictional claims in published maps and institutional affiliations.

\section{Author details}

${ }^{1}$ École de nutrition de I'Université Laval, Pavillon Paul-Comtois, Université Laval, 2425, rue de l'Agriculture, local 2412, Québec G1V 0A6, Canada. ${ }^{2}$ Axe d'endocrinologie et de néphrologie du Centre de Recherche du CHU de Québec-Université Laval, Québec, QC, Canada. ${ }^{3}$ Institut sur la nutrition et les aliments fonctionnels, Université Laval, Québec, QC, Canada.

Received: 15 October 2017 Accepted: 12 April 2018

Published online: 23 April 2018

\section{References}

1. Al Wattar BH, Mylrea-Lowndes B, Morgan C, Moore AP, Thangaratinam S. Use of dietary assessment tools in randomized trials evaluating diet-based 
interventions in pregnancy: a systematic review of literature. Curr Opin Obstet Gynecol. 2016;28(6):455-63.

2. Willet WC. Nutritional epidemiology. 3rd ed. New York: Oxford University Press; 2013.

3. Kipnis V, Midthune D, Freedman LS, Bingham S, Schatzkin A, Subar A, Carroll RJ. Empirical evidence of correlated biases in dietary assessment instruments and its implications. Am J Epidemiol. 2001;153(4):394-403.

4. Symonds ME, Ramsay MM. Maternal-fetal nutrition during pregnancy and lactation. Cambridge: Cambridge University Press edn; 2010

5. Kaiser L, Allen LH. Position of the American dietetic association: nutrition and lifestyle for a healthy pregnancy outcome. J Am Diet Assoc. 2008; 108(3):553-61.

6. Whitney EN, Cataldo CB, Rolfes SR. Understanding normal and clinical nutrition. USA: Wadsworth ed; 2002.

7. Augustine RA, Ladyman SR, Grattan DR. From feeding one to feeding many: hormone-induced changes in bodyweight homeostasis during pregnancy. JPhysiol. 2008;586(2):387-97.

8. Fowles ER, Fowles SL. Healthy eating during pregnancy: determinants and supportive strategies. J Community Health Nurs. 2008;25(3):138-52.

9. Crozier SR, Inskip HM, Godfrey KM, Cooper C, Robinson SM, Group SWSS. Nausea and vomiting in early pregnancy: effects on food intake and diet quality. Matern Child Nutr. 2016;13(4):e12389.

10. Hill B, Skouteris H, McCabe M, Milgrom J, Kent B, Herring SJ, Hartley-Clark L, Gale J. A conceptual model of psychosocial risk and protective factors for excessive gestational weight gain. Midwifery. 2013;29(2):110-4.

11. Fuller-Tyszkiewicz M, Skouteris $H$, Watson BE, Hill B. Body dissatisfaction during pregnancy: a systematic review of cross-sectional and prospective correlates. J Health Psychol. 2013;18(11):1411-21.

12. Bingham SA, Gill C, Welch A, Cassidy A, Runswick SA, Oakes S, Lubin R, Thurnham DI, Key TJ, Roe L, et al. Validation of dietary assessment methods in the UK arm of EPIC using weighed records, and 24-hour urinary nitrogen and potassium and serum vitamin C and carotenoids as biomarkers. Int J Epidemiol. 1997;26(Suppl 1):S137-51.

13. Coulston AM, Boushey CJ. Nutrition in the prevention and treatment of disease. Amsterdam: Academic Press; 2008.

14. Kipnis V, Midthune D, Freedman L, Bingham S, Day NE, Riboli E, Ferrari P, Carroll RJ. Bias in dietary-report instruments and its implications for nutritional epidemiology. Public Health Nutr. 2002;5(6A):915-23.

15. Arens-Volland AG, Spassova $L$, Bohn T. Promising approaches of computersupported dietary assessment and management-current research status and available applications. Int J Med Inform. 2015;84(12):997-1008.

16. Illner AK, Freisling H, Boeing H, Huybrechts I, Crispim SP, Slimani N. Review and evaluation of innovative technologies for measuring diet in nutritional epidemiology. Int J Epidemiol. 2012;41(4):1187-203.

17. Kristal AR, Kolar AS, Fisher JL, Plascak JJ, Stumbo PJ, Weiss R, Paskett ED. Evaluation of web-based, self-administered, graphical food frequency questionnaire. J Acad Nutr Diet. 2014;114(4):613-21.

18. Foster E, Hawkins A, Simpson E, Adamson AJ. Developing an interactive portion size assessment system (IPSAS) for use with children. J Hum Nutr Diet. 2014;27(Suppl 1):18-25.

19. Naska A, Lagiou A, Lagiou P. Dietary assessment methods in epidemiological research: current state of the art and future prospects. F1000Res. 2017;6:926

20. Dietary Assessment Primer [https://dietassessmentprimer.cancer.gov/] Accessed 20 July 2017

21. Butte NF, King JC. Energy requirements during pregnancy and lactation. Public Health Nutr. 2005;8(7A):1010-27.

22. Shatenstein $B, X u H$, Luo ZC, Fraser W. Relative validity of a food frequency questionnaire for pregnant women. Can J Diet Pract Res. 2011;72(2):60-9.

23. Gibson RS. Principles of nutritional assessment. 2nd ed. New York: Oxford University Press; 2005.

24. Ashman AM, Collins CE, Brown LJ, Rae KM, Rollo ME. Validation of a smartphone image-based dietary assessment method for pregnant women. Nutrients. 2017:9(1):73

25. Jacques S, Lemieux S, Lamarche B, Laramee C, Corneau L, Lapointe A, Tessier-Grenier M, Robitaille J. Development of a web-based 24-h dietary recall for a French-Canadian population. Nutrients. 2016;8(11):724.

26. Moshfegh AJ, Rhodes DG, Baer DJ, Murayi T, Clemens JC, Rumpler WV, Paul DR, Sebastian RS, Kuczynski KJ, Ingwersen LA, et al. The US Department of Agriculture Automated Multiple-Pass Method reduces bias in the collection of energy intakes. Am J Clin Nutr. 2008;88(2):324-32.
27. Canadian Nutrient File (cnf). [https:/food-nutrition.canada.ca/cnf-fce/index-eng.jsp]. Accessed 20 July 2017.

28. Lafrenière J, Lamarche $B$, Laramée $C$, et al. Validation of a newly automated web-based 24-hour dietary recall using fully controlled feeding studies. BMC Nutr. 2017;3:34

29. Lombard MJ, Steyn NP, Charlton KE, Senekal M. Application and interpretation of multiple statistical tests to evaluate validity of dietary intake assessment methods. Nutr J. 2015;14:40.

30. Vezina-Im LA, Godin G, Couillard C, Perron J, Lemieux S, Robitaille J. Validity and reliability of a brief self-reported questionnaire assessing fruit and vegetable consumption among pregnant women. BMC Public Health. 2016;16:982.

31. Masson LF, McNeill G, Tomany JO, Simpson JA, Peace HS, Wei L, Grubb DA, Bolton-Smith C. Statistical approaches for assessing the relative validity of a food-frequency questionnaire: use of correlation coefficients and the kappa statistic. Public Health Nutr. 2003;6(3):313-21.

32. Taren D, Dwyer J, Freedman L, Solomons NW. Dietary assessment methods: where do we go from here? Public Health Nutr. 2002;5(6A):1001-3.

33. Bland JM, Altman DG. Statistical methods for assessing agreement between two methods of clinical measurement. Lancet. 1986;1(8476):307-10.

34. Frankenfeld CL, Poudrier JK, Waters NM, Gillevet PM, Xu Y. Dietary intake measured from a self-administered, online 24-hour recall system compared with 4-day diet records in an adult US population. J Acad Nutr Diet. 2012; 112(10):1642-7.

35. Timon CM, Blain RJ, McNulty B, Kehoe L, Evans K, Walton J, Flynn A, Gibney ER. The development, validation, and user evaluation of Foodbook24: a web-based dietary assessment tool developed for the Irish adult population. J Med Internet Res. 2017;19(5):e158.

36. Comrie F, Masson LF, McNeill G. A novel online food recall checklist for use in an undergraduate student population: a comparison with diet diaries. Nutr J. 2009:8:13.

37. De Keyzer W, Huybrechts I, De Vriendt V, Vandevijvere S, Slimani N, Van Oyen H, De Henauw S. Repeated 24-hour recalls versus dietary records for estimating nutrient intakes in a national food consumption survey. Food Nutr Res. 2011;55 https://doi.org/10.3402/fnr.v55i0.7307

38. Nelson M, Atkinson M, Darbyshire S. Food photography. I: the perception of food portion size from photographs. Br J Nutr. 1994;72(5):649-63.

39. Ovaskainen ML, Paturi M, Reinivuo H, Hannila ML, Sinkko H, Lehtisalo J, Pynnonen-Polari O, Mannisto S. Accuracy in the estimation of food servings against the portions in food photographs. Eur J Clin Nutr. 2008;62(5):674-81.

40. Turconi G, Guarcello M, Berzolari FG, Carolei A, Bazzano R, Roggi C. An evaluation of a colour food photography atlas as a tool for quantifying food portion size in epidemiological dietary surveys. Eur J Clin Nutr. 2005;59(8):923-31.

41. Block $G$. A review of validations of dietary assessment methods. Am J Epidemiol. 1982;115(4):492-505.

42. Latva-Pukkila $U$, Isolauri $E$, Laitinen $K$. Dietary and clinical impacts of nausea and vomiting during pregnancy. J Hum Nutr Diet. 2010;23(1):69-77.

43. Mantovani E, Filippini F, Bortolus R, Franchi M. Folic acid supplementation and preterm birth: results from observational studies. Biomed Res Int. 2014; 2014:481914.

44. Goh YI, Koren G. Folic acid in pregnancy and fetal outcomes. J Obstet Gynaecol. 2008;28(1):3-13.

45. Green NS. Folic acid supplementation and prevention of birth defects. Jutr. 2002;132(8 Suppl):2356S-60S.

\section{Ready to submit your research? Choose BMC and benefit from:}

- fast, convenient online submission

- thorough peer review by experienced researchers in your field

- rapid publication on acceptance

- support for research data, including large and complex data types

- gold Open Access which fosters wider collaboration and increased citations

- maximum visibility for your research: over $100 \mathrm{M}$ website views per year

At BMC, research is always in progress.

Learn more biomedcentral.com/submissions 